\title{
O gue faz o Brasil na República Mundial DAS LETRAS?
}

\author{
What is Brazil doing in the World Republic of \\ Letters?
}

\author{
Anderson Bastos Martins*
}

\begin{abstract}
RESUMO
Este artigo tem por objetivo central contribuir para a discussão acerca dos efeitos da globalização cultural e econômica sobre a produção e a recepção da literatura brasileira contemporânea. Para tanto, recorremos a uma breve revisão da literatura especializada voltada para o debate em torno do conceito de globalização, bem como das possíveis inter-relações entre as teorias da globalização e os estudos literários. Em segundo lugar, buscamos na noção de "(in)tradutibilidade”, de acordo com recentes pesquisas no campo da literatura comparada, mais um aporte para a criação de um diálogo entre a fase atual da globalização e a literatura e a crítica literária no Brasil. Por último, a publicação de um número da revista Granta, dedicado a jovens autores brasileiros, representa um apoio, buscado na escrita ficcional, para melhor compreensão das circunstâncias históricas e dos construtos teóricos aqui discutidos.
\end{abstract}

Palavras-chave: literatura brasileira contemporânea; globalização; literatura comparada; (in)tradutibilidade.

\begin{abstract}
This article seeks mainly to contribute to the discussion of the effects of cultural and economic globalization on both the production and the reception of contemporary Bra-zilian literature. In so doing, we conduct a brief review of the specialized literature con-cerning the concept of globalization as well as potential interconnections between theo-ries of globalization

* Universidade Federal de São João del-Rei.
\end{abstract}


and literary studies. Secondly, we resort to the notion of "(un) translatability", as presented in recent research coming from the area of compara-tive literature, a further element conducive to the dialogue between the current stage of globalization and both literature and literary criticism in Brazil. Lastly, the publication of a volume of Granta, dedicated to young Brazilian authors, bolsters, by means of fic-tional writing, a better understanding of the historical circumstances and the theoretical constructs discussed here.

Keywords: contemporary Brazilian literature; globalization; comparative literature; (un)translatability.

\section{INTRODUÇÃo}

O título deste artigo faz alusão ao livro de Pascale Casanova, A república mundial das letras, em que a autora avalia a história da legitimação literária desde o início do debate acerca da literatura mundial, passando pela efervescência cultural do modernismo europeu até chegar ao final do século 20, quando a literatura começou a ser interpelada pelos processos de globalização da cultura. Embora a literatura brasileira seja brevemente incluída nas preocupações de Casanova, o fato de o livro ter sido publicado originalmente em 1999 o torna cego a várias das modificações sofridas pelo mercado editorial e pelas tecnologias, lícitas e ilícitas, de distribuição e divulgação de textos lite-rários. O conceito de legitimação literária de Casanova cai por terra diante das potencia-lidades de circulação dos produtos literários engendradas pelas atuais tecnologias de criação e compartilhamento de dados. Outro elemento que permanece ausente do livro é a ascensão daquilo que poderíamos tratar como "literatura enquanto evento", fenômeno que escancara a presença de forças de mercado na produção e na recepção das obras literárias e se torna visível na multiplicação permanente de prêmios e feiras que promo-vem uma infinidade de títulos, além de movimentarem recursos financeiros que deixari-am incrédulo e talvez invejoso o endividado Dostoiévski. É justamente nesse cenário desenhado pelo século 21 que eu gostaria de refletir sobre o trânsito da literatura brasi-leira num contexto cada vez mais globalizado. Antes disso, porém, creio ser importante visitar, ainda que brevemente, um recorte da literatura especializada, que tem procurado compreender o impacto da globalização sobre a produção e sobre a crítica das obras literárias.

Uma vez que a definição de literatura já é entendida como um esforço condena-do ao fracasso, poderíamos imaginar que um conceito como o de globalização, buscado em áreas das ciências humanas que se querem 
menos dependentes da metaforização enquanto método de conhecimento, como a geografia e a sociologia, traria uma dose maior de solidez aos estudos sobre a literatura contemporânea. Entretanto, temos uma sensação bastante diferente quando lemos as páginas iniciais do primeiro capítulo de Globalization and literature, de Suman Gupta, sintomaticamente intitulado "As nuances da globalização". Conforme podemos ler ali, "a 'globalização' está hoje disponível como uma das palavras mais marcadamente mutáveis e mais intensamente conotativas de nosso vocabulário" (GUPTA, 2009, p. 9 , tradução e grifo nossos). Na sequência desse comentário, Suman Gupta recorre a Norman Fairclough, para quem

é impossível ignorarmos o fato de que, embora a globalização seja uma série de mudanças que realmente estão ocorrendo no mundo (ainda que a definição do que está incluído nessa série seja um ponto muito controverso), ela é também uma palavra que recentemente se tornou proeminente na forma com que essas mesmas mudanças são representadas (FAIRCLOUGH, apud GUPTA, 2009, p. 9, tradução e grifo nossos).

A partir dessas considerações, proponho que pensar a globalização simultanea-mente como um fato e como um construto linguístico é a maneira mais segura de trazê-la para o universo dos estudos literários, uma vez que a literatura enquanto arte da re-presentação é comumente pensada como resultante da interação, nunca inteiramente apreciável, entre o mundo enquanto realidade e o mundo enquanto palavra. Além disso, diante dos desafios e dilemas suscitados pelos processos globalizantes contemporâneos, refletir sobre a globalização em suas potencialidades literárias pode redundar num traba-lho significativo de avaliação da literatura em suas relações com a política.

\section{REVENDO CONCEITOS}

A leitura de alguns dos principais títulos dedicados ao tema da globalização nos dá a possibilidade de perceber a existência de duas correntes principais na bibliografia disponível. De um lado, encontramos autores dispostos a tratar a globalização como um fenômeno mais limitado e engendrado a partir de meados do século 20 , mais exatamente no período de reconstrução da Europa devastada pela Segunda Grande Guerra e do sur-gimento dos Estados Unidos como uma de duas grandes potências políticas e econômi-cas do pós-guerra. Nessa perspectiva, a globalização corresponderia à disseminação de políticas liberais e objetos culturais produzidos por uma nação com pendores fortemente hegemônicos, a saber, os Estados 
Unidos e sua cultura de massa que, desde as interven-ções do país no conflito europeu, granjeavam para si um forte apelo internacional por meio de musicais, filmes e do culto à celebridade. Os críticos da globalização nessa visão sincrônica incluem figuras de destaque situadas ao lado esquerdo do pensamento teórico e político, como Fredric Jameson (1996), David Harvey (1990), Zygmunt Bauman (2001) e Anthony Giddens (1990). Para esses pensadores, a globalização, a despeito de suas potencialidades de modificação das relações políticas, econômicas e culturais, acabou se constituindo - ou desde a origem foi planejada - como principal motor da norte-americanização do mundo contemporâneo. A ideia do pensamento único, tão fre-quente nas críticas feitas às políticas neoliberais defendidas agressivamente pelas prin-cipais instituições do capitalismo global contemporâneo, dá também o mote àqueles que enxergam na globalização uma forma de estabelecimento de algumas poucas culturas e políticas hegemônicas que funcionam e se reproduzem por meio de um processo de ex-clusão e aniquilação de diferenças.

O contraponto a essa visão pode ser encontrado no trabalho de Roland Robert-son (1992), que pensa a globalização como um antigo processo diacrônico com fases de significativo recrudescimento, como a que se vê na atualidade proporcionada em grande medida pela revolução tecnológica das últimas décadas. Nessa perspectiva de cunho historicista, Robertson defende que, em lugar da exclusão e da homogeneização, os pro-cessos globalizantes se formam dentro de um circuito interminável, portanto não dialéti-co, que envolve universalismo e particularismo, unidade e diversidade, semelhança e diferença, o que impossibilitaria qualquer projeto hegemônico que se apoiasse no funci-onamento da globalização em suas vertentes mais concretas, como a globalização nas relações econômicas. Em última instância, Robertson conclui que

[a] globalização do final do século 20 envolve a institucionalização tanto da universalização do particularismo quanto da particularização do universalismo e pode ser indicada de forma mais específica como sendo constituída dos processos interpenetrantes de socialização, individualização do sistema internacional de sociedades e concretização do sentido de humanidade. (ROBERTSON, 2010, p. 27, tradução nossa)

Na formulação acima, a globalização deixa de ser o grande problema dos dias atuais, ou seja, desveste-se de uma aura marcada pelo temor e pela animosidade em re-lação ao poderio dos Estados Unidos - sem abrir mão de questionar os inúmeros efeitos deletérios desse gigantesco poder concedido a uma única nação - e passa a ser percebida como abertura para a renovação da sociedade global em formação após o grande trauma do 
ataque às Torres Gêmeas em 11 de setembro de 2001. Além disso, as duas primeiras décadas do século atual se deixaram marcar por profundas transformações em sua relação com o capital, mais que nunca um componente fundamental de qualquer coletividade, mas que se mostra cada vez mais volátil e, portanto, inapreensível. Na esteira dessa fluidificação do dinheiro, as condições propiciatórias de uma hegemonia centralizada em uma só nação vão se tornando inalcançáveis.

Essa nova configuração das relações internacionais não só traz consigo a possi-bilidade de diluição das instâncias fixas de poder como também desvincula a noção de globalização do conceito de centro. Esse processo está sendo estudado exaustivamente por sociólogos e teóricos da cultura interessados na reconfiguração das relações entre centro e periferia. Ao cunhar o termo "glocalização", Roland Robertson (1995) traz seu pensamento para o cerne das teorias que buscam no cerceamento da globalização um antídoto para os males da contemporaneidade. E se retomarmos a dualidade da percep-ção do processo de globalização como fato real ao mesmo tempo que construto linguís-tico, podemos começar a investigar como a literatura pode participar desse debate que promete ser de fundamental importância para a reflexão em torno de uma política das letras.

\section{A Literatura BRASILEIRA E A GLOBALIZAÇÃo}

No intuito de esclarecer como esses apontamentos podem dizer respeito à anto-logização da literatura brasileira contemporânea, busco uma aproximação entre eles e a publicação do número 121 da revista britânica Granta, totalmente dedicado a jovens autores do Brasil. A antologia foi publicada em primeiro lugar em Londres, em tradução para o inglês, para somente depois aparecer em versão brasileira, lançada na FLIP de 2012. Sem dúvida, esse número da Granta constitui-se numa ótima oportunidade de pesquisa sobre a inserção global da ficção produzida no Brasil a partir de uma das cida-des mais globais do planeta e que talvez tenha lançado a primeira antologia original-mente internacional da literatura brasileira, uma vez que a Granta é uma revista de assi-natura trimestral distribuída para diversos países e em vários idiomas.

Os textos selecionados foram traduzidos para o inglês, e a edição brasileira difere muito pouco da britânica. Apenas as seleções, inclusões e exclusões que podemos encontrar nas traduções já bastariam para interessantes reflexões sobre a discursividade posta em movimento para que fosse possível levar uma amostra da literatura brasileira contemporânea a um público internacional. Por essa razão, julgo proveitoso anteceder meus comentários sobre dois dos textos incluídos na revista de um breve apanhado das ideias de Emily Apter a respeito do traduzível e do intraduzível na literatura comparada. 
No mercado da diferença terceiro-mundista, quais os produtos que vendem? Um autor que apela para o universalismo ou para a filosofia religiosa não secular? Um escritor dissidente? Um autor do subcontinente [asiático] que explora o exotismo ou alguém que investiga a identidade pós-colonial? Um escritor do Círculo do Pacífico que reforça estereótipos essencialistas de asiaticidade, ou alguém que abraça conceitos e vanguardas literárias do Ocidente? Um escritor africano tradicional ou um afro-futurista? Obviamente, as escolhas dependem em grande medida de caprichos da moda e da política, mas uma coisa é certa: embora o atual mercado da literatura mundial seja volátil e imprevisível, é possível identificar um cânone que poderia ser chamado de "em-tradução" (dominado por autores ligados à PEN e à UNESCO) e que supera seus rivais mantidos no anonimato.

Poderíamos nos perguntar, dessa forma, até que ponto os escritores "estrangeiros" com maiores ambições estão escrevendo, consciente ou inconscientemente, para mercados internacionais, criando para seus textos condições de tradutibilidade. Embora a própria noção de tradutibilidade muitas vezes nos escape (...), está claro que certos originais se apresentam como candidatos mais bem preparados para a tradução do que outros. (APTER, 2011, p. 142-3, tradução e grifo nossos)

Não há por que negar que a revista Granta surge como uma possibilidade de ampliação do mercado internacional da literatura brasileira. Mas quando lemos que os textos incluídos na antologia foram selecionados por uma comissão julgadora a partir de submissões apresentadas pelos próprios autores, a busca pela "tradutibilidade" global passa a ser uma questão que merece ser avaliada quando se lê criticamente o volume dedicado ao Brasil. Relançando a pergunta formulada por Emily Apter, cabe indagar se os "melhores jovens escritores brasileiros" produziram seus textos no intuito de serem compreendidos confortavelmente por uma elite leitora transnacional. Não sendo possível ler aqui todos os vinte textos à luz do critério estabelecido por Emily Apter, gostaria de fazer alguns breves comentários sobre dois deles.

Não fui pelos tratamentos dentários, nem pela dança cigana, nem pelo tuiča, nem pelo Castelo de Bran. Também não fui cobrar dívidas hereditárias, fazer buscas genealógicas ou comprar exemplares raros da avanguardea literarea romaneasca. Não me interessava a brisa que alisa o Dambovita, o canto noturno do strigoi ou a vida selvagem no Delta do Danúbio. Também não fui para esquecer um amor perdido ou seguir rastros de mim mesmo. Fui porque outros me pediram e conheci Martina. Os cabelos mais perfumados do Leste, os caravaggiescos cabelos de Martina Ptyx. Eles me perturbaram e me atraíram como um convite de união anatômica. Fetiche? Também. Mas nada disso importa muito agora, nem importou tanto assim naqueles dias. Fui a Bucareste atrás das caixas de Neagu, conheci Martina e voltei com as coisas do velho Stefan. (ERBER, 2012, p. 27) 
Esse é o parágrafo de abertura de "Aquele vento na praça", de Laura Erber, cujo narrador é um artista plástico inglês de pouca expressão encarregado de viajar a Buca-reste a fim de comprar obras do artista plástico anglo-romeno Paul Neagu. O conto mescla personagens fictícios, como o narrador e Stefan e Martina Ptyx, pai e filha que possuem algumas das peças de Neagu que o narrador deseja adquirir, e ficcionalizações de personagens reais, como o próprio Paul Neagu. No âmbito da tradutibilidade interna-cional, o que se lê é uma narrativa recheada de um sem número de referências a grandes nomes e instituições da cultura contemporânea global, como Anish Kapoor e os museus Tate Modern e V\&A nas artes plásticas, Loreena McKennit, no movimento de interna-cionalização da música irlandesa tradicional, Lars von Trier no cinema, Proust e Balzac, na alta literatura francesa, além de Paulo Coelho, o único artista brasileiro conhecido por algum habitante de um vilarejo romeno, informação que o narrador sutilmente oferece ao leitor.

Concentrando-me apenas no parágrafo citado, destaco a presença ali de referên-cias que, bem ao gosto da história literária brasileira, poderíamos pensar como o "exótico romeno". Emprego o termo "exótico" na tentativa de compreender o recurso à citação de elementos da cultura que são muito pouco conhecidos da grande maioria dos leitores brasileiros. Afinal de contas, não imagino que muitos dos consumidores da literatura brasileira saibam que a "tuiča" é uma aguardente de ameixas com forte teor alcoólico, ou que, na mitologia dos dácios, o "strigoi" é um espírito que se comporta à semelhança dos vampiros. É tentador imaginar uma explicação para esse tipo de escolha realizada por Laura Erber. Há não muitas décadas atrás, não éramos nós, professores e pesquisadores de literatura, críticos e autores literários, que nos queixávamos do tratamento exoticista/localista que as universidades estrangeiras conferiam à literatura brasileira? E como compreender a referência a tais componentes intraduziveis da cultura romena sendo feita ao lado de nomes marcantes de uma cultura global, como acabamos de citar? Em outras palavras, o que pensar desse choque entre aquilo que não se traduz e aquilo que não carece de tradução num texto brasileiro supostamente produzido para um público internacional?

Parece-me que o narrador do conto de Laura Erber apresenta características que o credenciam como uma espécie de resposta à desconfiança com que a comunidade crítica internacional de décadas passadas recebia os autores periféricos, num misto entre o fascínio por paisagens e comportamentos inusitados e a hesitação em tratar com maior seriedade as contribuições que poderiam ser oferecidas por esses intelectuais de além-mar ao debate acadêmico a respeito do estatuto moderno da obra literária. Assim, Phillip Honeysuckle - é este o nome artístico do narrador inglês de Erber - possui as marcas necessárias para que seja lido como um indivíduo cosmopolita 
que percorre diversos universos estéticos, adquirindo, assim, familiaridade tanto com o exótico e local quanto com o global. Dessa forma, o narrador inglês, disfarce autoral criado pela escritora bra-sileira, escapa ao confinamento em categorias associadas ao indivíduo do Novo/Terceiro Mundo pela intelectualidade do assim chamado Velho/Primeiro Mundo, o que faz de Honeysuckle um cidadão do mundo cujo testemunho desse Mundo Novo, ao mesmo tempo de primeira e de terceira, que se configura nos intercâmbios e traduções engendradas na globalização, está pronto para ser recebido como uma contribuição im-portante para a compreensão e a teorização de uma cultura contemporânea marcada si-multaneamente pela nostalgia das raízes e pela aventura das asas.

Cumpre indagar, porém, se o autor brasileiro necessita recorrer a um disfarce "estrangeiro" para criar uma aura de aceitabilidade internacional para seus textos. É natural que o parágrafo acima traga essa suspeita para quem o lê, embora a intenção seja outra. O "disfarce" não constitui uma dissimulação da verdadeira identidade, mas um recurso de demonstração do caráter cosmopolita e global da jovem intelectualidade bra-sileira forjada nas últimas décadas de intensa transformação do papel desempenhado pelo Brasil no cenário cultural e econômico do novo século. Assim, o escritor brasileiro contemporâneo não é um terceiro-mundista disfarçado de primeiro-mundista de segunda ordem, mas um cidadão global que ajuda a abolir essas categorias consagradas, porém desgastadas, que já não mais nos explicam o mundo. Philip Honeysuckle é a "periferia no centro" que não deseja passar de periferia a centro.

O segundo texto publicado na revista Granta e que gostaria de comentar possui certas analogias com o conto de Laura Erber. Embora dispense o narrador e o cenário estrangeiros, na base do problema enfrentado na narrativa estão várias referências cultu-rais e mercadológicas do circuito globalizado do mundo contemporâneo, ou seja, assim como em "Aquele vento na praça”, a globalização surge novamente como um espectro, dessa vez mais assustador, com certos ares ameaçadores que precisam ser combatidos se o mundo quiser continuar sendo um local habitável.

Nos anos dez do século XXI, mais discreto e eficaz que derrubar os barracos dos morros da Zona Sul foi militarizar a área, construir muros de três metros de altura nas fronteiras das favelas e retirar gradualmente o oxigênio de seus moradores. Do processo inicial de asfixia fizeram parte reformas que maquiaram o improviso, encarceraram a área e abriram caminho, ainda que não tenham alargado as ladeiras e vielas que sangram pelo morro, para a chegada de novos personagens: oficiais das Forças Armadas brasileiras e suas ramificações mafiosas, empreiteiros, agentes imobiliários, estrangeiros, novos capitalistas, bancos, imprensa, bistrôs, galerias de 
arte abstrata, American Apparel, lojas de frozen yogurt japonês no lugar do velho sapateiro, estudantes de design sustentados pelos pais ocupando sozinhos o ex-barraco onde vivia uma família de seis e agora é um Luxury Loft, um Upscale Condo's, um cubículo elegante com vista lateral para o mar e 350 mil dólares por 25 metros quadrados. Tratava-se da versão carioca de gentrificação, a ocupação de uma área urbana degradada por moradores de uma classe social mais rica com o afastamento de seus habitantes originais: Hackney, Greenwich Village, Williansburgh, Kreuzberg, Canal Saint Martin, Vidigal, Cantagalo, Rocinha, Pavão-Pavãozinho, Chapéu Mangueira, Providência, Saúde.

- Parece com arte. É difícil de explicar exatamente o que é, mas você conhece quando vê - disse certa vez Tomás Anselmo, apontando para o primeiro Starbucks no Morro da Rocinha, inaugurado no verão de 2015. (CUENCA, 2012, p. 40-1)

Tomás Anselmo é o narrador de "Antes da queda", de João Paulo Cuenca. Ele fala a partir de um ponto no futuro próximo, após a realização dos Jogos Olímpicos de 2016, e descreve um processo de crise pessoal em que não sabe ao certo se era o Rio de Janeiro que não mais queria saber dele, ou se era ele próprio que precisava abandonar sua cidade natal descaracterizada pelos efeitos do verdadeiro canteiro de obras em que a capital fluminense se transformou nos preparativos para os megaeventos esportivos ali sediados. o sentimento de não mais reconhecer o Rio de Janeiro de sua adolescência, ou seja, o Rio enquanto metrópole brasileira, provoca em Tomás Anselmo certa paralisia autodestrutiva, uma incapacidade de viver numa cidade abruptamente convertida em metrópole da globalização, onde

no lugar de bares e restaurantes e boates de nomes antigos que perderam o sentido como Penafiel, Luna Bar, Garage, Real Astoria, 69, Carlitos, Basement, Giotto, Bunker e Caneco 70, monstros de vidro espelhado, a irracional multiplicação das farmácias e drogarias, várias por quarteirão. (CUENCA, 2012, p. 45)

De volta às propostas de Emily Apter, podemos imaginar, caso nos solidarizemos com Tomás Anselmo, que a fácil tradutibilidade representada pelas farmácias clonadas em todas as esquinas das cidades brasileiras e pelas marcas internacionais como American Apparel e Starbucks serve de advertência diante de um Rio de Janeiro - ou de um Brasil - que a adesão efusiva aos valores e referências globais vai tornando intradu-zível a si próprio. Não por acaso, as palavras finais do texto de Cuenca (2012, p. 48) apresentam o seguinte veredito enunciado pelo narrador: "Mas logo tudo iria desapare-cer. E ele [Tomás] também”.

o que se percebe em "Antes da queda" é uma incapacidade de decodificar o texto global que o novo Rio de Janeiro apresenta a seus moradores 
e habitués. É como se a língua em que esse texto urbano fora escrita até alguns anos atrás estivesse morrendo e sendo rapidamente substituída por um idioma internacional que, embora se possa com-preender - com certo esforço por parte dos mais velhos e quase naturalmente pelos cita-dinos mais jovens - nunca será possível amar como se ama a língua pátria, o idioma em que choramos e rimos pela primeira vez. Tomás Anselmo, bem como todos os que se incomodam com o avanço da globalização enquanto homogeneização do mundo, temem que o excesso de tradutibilidade à sua volta resulte num apagamento de sua memória afetiva em relação à cidade de seu nascimento. o novo - nesse caso, o mesmo - impede o reconhecimento do velho - nesse caso, o outro, numa inversão da costumeira associa-ção entre novidade e alteridade e entre antiguidade e fixidez.

Os dois textos aqui comentados embutem uma reflexão sobre a globalização que aponta para caminhos bastante diversos. Se "Aquele vento na praça" prefigura um espa-ço novo de inserção da intelectualidade brasileira no cenário transnacional das trocas culturais do novo século - ainda que o impacto dessa inserção seja sentido somente por uma parcela reduzida da população compreendida por um grupo seleto de jovens cos-mopolitas -, as meditações de Tomás Anselmo são marcadas pelo temor da globalização como um fator de apagamento da memória de experiências responsáveis pela criação dos elos de coletividade e identidade.

Esses posicionamentos diferenciais encontrados nos dois textos não podem, ao menos por ora, ser equacionados, embora seja de grande importância rever toda uma história da literatura brasileira centrada em seu papel formador da nação. Os tempos novos exigem essas configurações, como nos lembrou Silviano Santiago em texto pu-blicado na Folha de S. Paulo e que cito aqui para finalizar esta parte de meu artigo.

Dou-me conta do esgotamento dos vários, diferenciados e notáveis "discursos de formação" que constituíram o paradigma desenvolvimentista como tarefa prioritária no crescimento da jovem nação brasileira.

A exaustão do paradigma não o aliena. Assinala, antes, que ele está a perder a condição de prioritário. Novas condições materiais definem o novo milênio brasileiro. Elas passam a exigir outro feixe amplo e crítico de discursos afins e complementares, que constituirão novo paradigma --o da "inserção" do Brasil no conjunto das nações. Tendo sido esclarecido (e não resolvido, obviamente) o modo como o sujeito brasileiro se automodelou como cidadão e acomodou nos trópicos a emancipação de uma sociedade jovem e moderna, delega-se hoje ao Estado nacional democrático papel e funções internacionais. Cosmopolita, a nação está habilitada a tomar assento no plenário do planeta. Automodelado, o sujeito discursivo --confessional, artístico ou científico-- pode e deve dar-se ao luxo da crítica e da autocrítica em novo paradigma. (SANTIAGO, 2014)

Revista Letras, Curitiba, N. 91 p. 75-88, JAN./JUN. 2015.

ISSN 2236-0999 (VERSÃo ELETRÔNICA) 


\section{A tAREFA DO TRADUTOR NA GLOBALIZAÇÃo}

O conceito de "intradutibilidade" apresentado por Emily Apter propõe a noção de que existem nas línguas - especialmente na nomeação de conceitos mais complexos - espaços de significação que não se podem transferir para outros idiomas. Todo falante de português que sente apreço pela estranha ideia de que "saudade" é uma palavra que não encontra equivalência em outras línguas está pensando dentro da esfera do intradu-zível. Como forma de desenvolver a tese e alertar os estudiosos de diversos setores das ciências humanas, Apter e outros dois colegas norte-americanos lançaram seu Dictionary of untranslatables: a philosophical lexicon, o qual recebeu uma resenha bastante severa do ensaísta Adam Gopnik, que enxerga ali uma dose muito intensa do desgastado conceito de "relativismo linguístico". Em linhas gerais, o relativismo linguístico foi desenvolvido por Bernard Lee Whorf e tenta trazer uma aura de cientificidade à hipóte-se de que cada comunidade idiomática se relaciona com o mundo de forma específica e determinada pelos limites do idioma de que dispõe.

Essa relação lembrada por Gopnik me leva a concluir que sua resenha oferece uma leitura excessivamente redutora da tese da intradutibilidade, a qual, por sua vez, funciona como antípoda do caráter irredutível conferido a esta no pensamento de Apter e seus colaboradores. Essa visão limitada se reproduz entre muitos pesquisadores en-volvidos atualmente com a literatura comparada, entre os quais parece haver um viés contrário ao ressurgimento do conceito de literatura mundial e da possibilidade de esta-belecimento de uma categoria que poderia ser denominada literatura global. Vale per-guntar, portanto, em que medida o enfoque sobre a intradutibilidade oferece suporte a essa tendência.

$\mathrm{Na}$ tentativa de oferecer o princípio de uma resposta, entendo esse investimento na esfera da intradutibilidade como uma forma de oposição ao suposto risco de que o estabelecimento de uma literatura mundial ao gosto do mercado e de um público leitor com acesso a uma globalização de massa revela a preocupação dos teóricos da literatura comparada com a eliminação da valorização da diferença e da significação inconclusiva que há décadas servem de esteio para os estudos literários acadêmicos. A ênfase sobre o intraduzível resguardaria a literatura de um movimento editorial transnacional disposto a expandir seu alcance ao redor do planeta sem correr o risco de lançar no mercado obras repletas de desafios referenciais ao leitor. Tais desafios - vimos alguns exemplos deles na leitura do conto de Laura Erber - são os elementos intraduzíveis que, como Apter nos leva a crer, a literatura mundial/global apagaria em favor da conquista de mercado e da criação das febres de leitura sobre as quais os cadernos de cultura nos informam frequentemente. 
Embora perca de vista essas implicações do trabalho de Emily Apter, Adam Gopnik conclui sua resenha em termos que falam ao temor embutido na tese da intradu-tibilidade bem como a meu próprio esforço de inserir a antologia de literatura brasileira contemporânea publicada pela revista Granta no debate mais amplo em torno das rela-ções entre literatura e globalização.

Não somos prisioneiros das línguas em que nascemos, mas somos seus cidadãos. E a cidadania é um amplo conceito que inclui comportamentos e rituais. (...)

Cidadãos de nossas línguas, agimos como cidadãos, participando, reformando, aceitando os rituais ou celebrando sua modificação, às vezes até mesmo votando em novas regras e novos líderes. Nenhuma palavra é inteiramente intraduzível, mas também nenhuma palavra é inteiramente transparente. Uma visão pragmática de como as palavras funcionam é a única que pode dar conta de nossos minúsculos, mas persistentes, triunfos e de nossos erros repentinos e cômicos. Às vezes elas criam sombra; às vezes elas vão direto ao ponto; muitas vezes, elas nos deixam na mão. (GOPNIK, 2014, p. 39, tradução nossa)

O subtítulo do texto assinado por Adam Gopnik - "Quanto efetivamente se per-de na tradução?" - faz-me pensar sobre o papel da crítica, que me parece ser o elemento ausente nas preocupações de Emily Apter e que não é diretamente citada pelo autor nor-te-americano. Refiro-me à crítica enquanto "consumação" da obra de arte, como nos lembra uma recente biografia de Walter Benjamin (EILAND; JENNINGS, 2014, p. 111) e que se aplica mais diretamente ao trabalho do crítico (acadêmico ou não), mas também ao teor crítico que subjaz a criação da obra de arte bem como sua recepção pro-fissional ou amadora.

Se pensarmos a globalização cultural conforme sugestão de Roland Robertson - "tanto (...) universalização do particularismo quanto (...) particularização do universa-lismo" -, podemos criar expectativas muito positivas de que a escrita literária não preci-sará necessariamente passar por um temido processo de pasteurização da diferença e do localismo - elementos emocionais e identitários de valor inapreensível - para ser global. Em outras palavras, a possibilidade de surgimento de um viés global de produção literá-ria não precisa ser encarada como um mal a ser combatido. A crítica - reitero que en-globo nesta categoria os variados atores do circuito de produção e recepção da literatura - como instrumento de cidadania no interior dos idiomas e das referências culturais deve assumir o papel de mediadora da tradutibilidade e da intradutibilidade, ciente de que não existe, nas trocas culturais e linguísticas globais, qualquer razão para condenação da transparência ou para celebração da opacidade como vícios ou virtudes em si. 
Estou ciente de que não se deve ignorar o risco de uma hegemonia cultural de cunho neoimperialista. No entanto, tomar ciência de um risco não deve servir de base para a criação de categorias absolutas que englobam o valor cultural ou a suposta ausência deste. Se não posso mais que encerrar minha discussão com palavras de efeito ima-gético e lírico, sugiro que, antes da queda, prestemos mais atenção àquele vento na praça.

\section{REFERÊNCIAS}

APTER, Emily. "Untranslatable" Algeria: The politics of linguicide. In: CONNELL, Liam; MARSH, Nicky. Literature and globalization: a reader. Nova York: Routledge, 2011. p. 140-6.

APTER, Emily; CASSIN, Barbara; LEZRA, Jacques; WOOD, Michael (Eds.). Dictionary of untranslatables: a philosophical lexicon. Princeton, NJ: Princeton Univer-sity Press, 2014.

BAUMAN, Zygmunt. Modernidade líquida. Tradução de: Plínio Dentzien. Rio de Ja-neiro: Zahar, 2001.

BHABHA, H. K. O bazar global e o clube dos cavalheiros ingleses. Tradução de: Tere-sa Dias Carneiro. Rio de Janeiro: Rocco, 2011.

CASANOVA, Pascale. A república mundial das letras. Tradução de: Marina Appenzel-ler. São Paulo: Estação Liberdade, 2002.

CONNELL, Liam; MARSH, Nicky. Literature and globalization: a reader. Nova York: Routledge, 2011.

CUENCA, João Paulo. Antes da queda. In: FERRONI, M. (ed.). Granta em Português. Rio de Janeiro: Objetiva/Alfaguara, 2012. v. 9, p. 37-48.

EILAND, Howard; JENNINGS, Michael W. Walter Benjamin: a critical life. Cambridge, Massachusetts; Londres: The Belknap Press of Harvard University Press, 2014.

ERBER, Laura. Aquele vento na praça. In: FERRONI, M. (ed.). Granta em Português. Rio de Janeiro: Objetiva/Alfaguara, 2012. v. 9, p. 25-36.

FERRoNI, M. (ed.). Granta em Português. Rio de Janeiro: Objetiva/Alfaguara, 2012. v. 9.

FREEMAN, J. Granta: The Magazine of New Writing. Londres: Granta Publications, out. 2012. v. 121.

GIDDENS, Anthony. The consequences of modernity. Cambridge: Polity, 1990.

GOPNIK, Adam. Word magic: how much really gets lost in translation? The New Yorker. Annals of Language. Nova York: Condé Nast, 26 maio 2014.

GUPTA, Suman. Globalization and literature. Malden: Polity Press, 2009.

HARVEY, David. The condition of postmodernity: an enquiry into the origins of cultur-al change. Oxford: Blackwell, 1990.

JAMESON, Fredric. Pós-modernismo: a lógica cultural do capitalismo tardio. Tradução de Maria Elisa Cevasco. São Paulo: Editora Ática, 1996.

ROBERTSON, Roland. Globalization: Social theory and global culture. Londres: Sage Publications, 1992. 
Glocalization: Time-space and homogeneity-heterogeneity. In: FEATHERSTONE, M.; LASH, S.; ROBERTSON, R. (Ed.). Global modernities. Londres: Sage Publications, 1995. p. 25-44

. The universalism-particularism issue. In: CONNELL, Liam; MARSH, Nicky. Literature and globalization: a reader. Nova York: Routledge, 2010. p. 22-27.

SANTIAGO, Silviano. Anatomia da formação. Folha de S. Paulo, São Paulo, 7 set. 2014. Caderno Ilustríssima. Disponível em <http://www1 folha.uol.com.br/fsp/ilustrissima/184397-anatomia-da-formacao.shtml>. Acesso em: 01 out. 2014.

Submetido em: 03/10/2014

Aceito em: 10/10/2014 